\title{
Development of Antimicrobial Hybrid Materials from Polylactic Acid and Nano-silver Coated Chitosan
}

\section{NOLLAPAN NOOTSUWAN ${ }^{1}$, KANKAVEE SUKTHAVORN ${ }^{2}$, WORAWAT WATTANATHANA ${ }^{1}$, SUCHADA JONGRUNGRUANGCHOK ${ }^{3}$, CHATCHAI VERANITISAGUL ${ }^{2}$, NATTAMON KOONSAENG ${ }^{4}$ and APIRAT LAOBUTHEE ${ }^{1 *}$}

\author{
${ }^{1}$ Department of Materials Engineering, Faculty of Engineering, Kasetsart University, \\ Ladyao, Chatuchak, Bangkok 10900, Thailand. \\ ${ }^{2}$ Department of Materials and Metallurgical Engineering, Faculty of Engineering, \\ Rajamangala University of Technology Thanyaburi, Pathumthani 12110, Thailand. \\ ${ }^{3}$ Department of Pharmaceutical Chemistry, Faculty of Pharmacy, Rangsit University, \\ Pathumthani 12000, Thailand. \\ ${ }^{4}$ Department of Chemistry, Faculty of Science, Kasetsart University, Ladyao, \\ Chatuchak, Bangkok 10900, Thailand. \\ ${ }^{*}$ Corresponding author E-mail: fengapl@ku.ac.th
}

http://dx.doi.org/10.13005/ojc/340210

(Received: December 12, 2017; Accepted: January 20, 2018)

\begin{abstract}
This work aims to prepare chitosan (CS) coated with nano-silver as a filler for polylactic acid (PLA) to develop novel hybrid materials with antimicrobial property. Nano-silver coated chitosan with different silver contents was prepared by reduction of silver nitrate using benzoxazine as a reducing agent. The obtained nanosilver-coated chitosan exhibited the antimicrobial property against S. aureus, B. subtilis, M. luteus, E. coli, P. aeruginosa and C. albicans. Among all the prepared chitosan coated with nanosilver (CS-Ag), 10CS-Ag (the silver content of $8.4 \%$ by weight from thermogravimetric analysis) showed the best antimicrobial activity. Therefore, 10CS-Ag was selected to be a filler for making compound pellets with polylactic acid (PLA). According to melt flow index (MFI) study of CSAg-PLA compounding, the hybrid materials between CSAg and PLA were prepared by compression molding. The hybrid materials with $3 \%$ by weight of 10CS-Ag in PLA matrix (3CSAg-PLA) revealed the antibacterial property of $99.99 \%$ inhibition. This work showed the possibility of developing the hybrid materials between CSAg and PLA as antimicrobial products.
\end{abstract}

Keywords: Chitosan, Nano-silver, Polylactic acid, Hybrid materials, Antimicrobial properties.

This is an Open Access article licensed under a Creative Commons Attribution-NonCommercial-ShareAlike 4.0 International License (https://creativecommons.org/licenses/by-nc-sa/4.0/), which permits unrestricted NonCommercial use, distribution and reproduction in any medium, provided the original work is properly cited. 


\section{INTRODUCTION}

Plastics play important role for our everyday life due to its cheap price, light weight and variety of applications. Plastics can be processed into different shapes so they are now replacing the usage of woods, metals and ceramics. Therefore, the demand for plastics is drastically increasing. However, a prevalence use of petroleumbased plastics leads to environmental problems as they take very long time to decompose ${ }^{1-3}$. Moreover, the shortage of petroleum and crude oil is also the issue $^{4}$. To solve the problems mentioned, many researchers and industries develop the new products from biodegradable plastics, especially polylactic acid (PLA). Polylactic acid is one of the best choice of biodegradable plastics since it offers many advantages. The production of PLA is renewable and consumes low energy. With these reasons, PLA is the eco-friendly material that is now widely used as plastic bags, food containers as well as medical equipment. However, the use of neat PLA is not widespread because certain properties are needed to be improved. Hybrid materials are composite materials fabricated to have specific properties that are suitable for certain applications. Normally, hybrid materials are consisting of a polymer matrix and a filler. The addition of fillers commonly introduces the desired properties of the hybrid materials ${ }^{5}$.

Chitosan (CS) is the product from deacetylation reaction of chitin, which comes from the peripheral parts of crustacean organisms such as shrimps and crabs $^{6-9}$. Unlike many synthesized polymers, chitosan has notable properties, e.g. biodegradation and biocompatibility. Moreover, the compounds produced from the degradation of chitosan are non-toxic, non-allergic, and non-carcinogenic ${ }^{10-12}$. Furthermore, chitosan has various applications in several industries such as cosmetics and toiletries, pharmaceutical, agriculture, textiles, foods as well as chemical industries $^{13-17}$. Due to the mentioned properties of chitosan, it would be possible to use as a biodegradable filler for PLA to produce novel hybrid materials of PLA.
Silver is renowned for its antimicrobial activity with a broad range of activity. It was ubiquitous that silver in any oxidation states ( $\mathrm{AgO}$, $\mathrm{Ag}^{+}, \mathrm{Ag}^{2+}$, and $\mathrm{Ag}^{3+}$ ) is commonly used as an antimicrobial agent against numerous bacterial strains and micro-organisms ${ }^{18}$. Especially in the nanoscale, silver nanoparticles (AgNPs), with the particle sizes smaller than $100 \mathrm{~nm}$ consisting of 20-15,000 silver atoms, show incredible physical, chemical and biological properties, and antibacterial activity ${ }^{19}$. The reason for the prevailing use of the AgNPs antibacterial agent is due to low toxicity toward mammalian cells ${ }^{20-21}$.

Recently, many efforts have been paid on hybrid of metallic salts and biopolymers on the basis of polymer characteristics with metal ion properties. Chitosan with high chelating strength for numerous metal ions is a promising candidate for the metallic cations and biopolymer hybrids. The chelation increases the number of metal ions on the polymer surface and therefore inhibits the particle growth ${ }^{22}$. It was proved that various nanoparticles in combination with chitosan are potential candidate in biomedical applications due to advantages of biodegradability, antibacterial and superb chelating characteristics. Numerous works have been done using chitosan with different nanoparticles. Farouk et al. integrated the $\mathrm{ZnO}$ nanoparticles with chitosan to show the effective antibacterial properties ${ }^{23}$ while AbdElhady et al. used the similar materials for the induced antibacterial property and UV protection in fabrics ${ }^{24}$. Interestingly, both silver and chitosan are antibacterial agents, so CS-AgNPs composite material is likely to be more antibacterial effective ${ }^{25}$. Thus, many researches on this point have been carried out. For example, Arif and co-workers developed the cotton fabrics with chitosan-silver nanoparticles ${ }^{26}$. In our study, we therefore need to extend state-of-the-art to further investigate the novel antimicrobial materials from both the biodegradable matrix (PLA) and biomaterial filler (chitosan) with silver nanoparticles. To prepare the nanosilver coated chitosan for using as a filler for the desired hybrid materials, the silver nanoparticles was introduced into the surface of chitosan by chemical reduction of silver nitrate using benzoxazine which has been firstly reported by our 
group $^{27}$. Furthermore, the detailed characterization on the structural, mechanical, and antimicrobial properties of the obtained hybrid materials are examined.

\section{EXPERIMENTAL}

\section{Materials}

Chitosan with molecular weight of 150,000

$\mathrm{Da}$ and deacetylation degree of 0.95 was purchased from SEA FRESH CHITOSAN (Lab) Co., Ltd. (Thailand). Silver nitrate $\left(\mathrm{AgNO}_{3}\right.$, Analytical reagent grade) with molecular weight of 108 $\mathrm{Da}$ was obtained from $\mathrm{POCH}$ company. Dichloromethane $\left(\mathrm{CH}_{2} \mathrm{Cl}_{2}\right.$, commercial grade) with molecular weight of $84.93 \mathrm{Da}$ was received from Lab Scan. 3,4-Dihydro-3,6-dimethyl-1,3-2Hbenzoxazine was synthesized according to our previous literature ${ }^{27}$ for using as a reducing agent for silver(I) ion from silver nitrate. Acetone $\left(\mathrm{CH}_{3} \mathrm{COCH}_{3}\right.$, commercial grade) with molecular weight of $58 \mathrm{Da}$ was purchased from Alcohol Paint Solvent, Thinner \& Chemistry Supply Co., Ltd. Anhydrous sodium sulphate with molecular weight of 142.04 Da was purchased from Riedel-deHaen Co., Ltd. Polylactic acid used in the study was a commercial grade (PLA 2003D) and obtained from Nature works LLC, USA. All the chemicals are used as received.

\section{Synthesis of nano-silver coated chitosan}

Chitosan with different masses, i.e. $20 \mathrm{~g}$, $15 \mathrm{~g}, 10 \mathrm{~g}$ and $2.5 \mathrm{~g}$, was subjected to coating with silver nanoparticles by the procedure reported in the literature ${ }^{27}$. The amounts of starting materials and nomenclatures are listed in Table 1.

Table 1: Amounts of starting materials for synthesis of nanosilver coated chitosans

\begin{tabular}{lcccc}
\hline Starting material & Chitosan coated with silver nanoparticles \\
& & & & \\
\hline & $2.5 C S-A g$ & 10 CS-Ag & $15 C S-A g$ & $20 C S-A g$ \\
Chitosan $(g)$ & 2.5 & 10 & 15 & 20 \\
Silver nitrate $(\mathrm{g})$ & 1 & 1 & 1 & 1 \\
The reducing agent $(\mathrm{g})$ & 1 & 1 & 1 & 1 \\
\hline
\end{tabular}

\section{Preparation of hybrid materials}

Polylactic acid was dried at $40{ }^{\circ} \mathrm{C} 24 \mathrm{~h}$ in ambient air to remove adsorbed moisture. The obtained polylactic acid was mixed with nano-silver coated chitosan with the content of 1, 3, 5 and 7 phr. Hereinafter, they would be named 1AgCS-PLA, 3AgCS-PLA, 5AgCS-PLA and 7Ag CS-PLA, respectively. The study on melt flow index (MFI) suggested that compression molding could be used to fabricate AgCS-PLA hybrid materials. The mixtures were compressed by using compression molding machine at $150{ }^{\circ} \mathrm{C}$ with a pressing time of $10 \mathrm{~min}$. under the pressure of 100 bar and the cooling time of $10 \mathrm{~min}$.

\section{Material characterization}

Fourier Transform Infrared (FTIR) spectra were recorded in the range $4000-600 \mathrm{~cm}^{-1}$ by a Perkin-Elmer 2000-FTIR, using $\mathrm{KBr}$ pellet technique for identifying functional groups of the specimens. Morphologies of all the powders were investigated by scanning electron microscope (Philips, XL30) using acceleration voltage of $5 \mathrm{kV}$. The samples were sputter-coated with gold to increase electrical conductivity. Thermogravimetric analysis (TGA) of chitosan and nanosilver coated chitosan was conducted by TGA analyzer from Mettler Toledo. The analysis was performed with the heating rate of $5^{\circ} \mathrm{C} / \mathrm{min}$. in $\mathrm{N}_{2}$ (20 psi) from 25 to $1000{ }^{\circ} \mathrm{C}$ under static air flow of 20 psi. Elemental analysis was studied by $X$-ray fluorescent spectrometer (Horiba XGT-2000W) with the X-ray tube operated at $50 \mathrm{kV}$ and $1 \mathrm{~mA}$. Differential scanning calorimeter (DSC) was performed by DSC analyzer from Mettler Toledo with a heating rate of $10{ }^{\circ} \mathrm{C} / \mathrm{min}$. from 0 to $250{ }^{\circ} \mathrm{C}$. Impact test was performed using a lzod impact tester (CEAST: Model 6546). The samples for impact testing were prepared by compression molding according to the ASTM D256 standard. Flexural test was performed 
using a universal tensile testing machine (COMETECH:B1/E type). The specimens for flexural testing were prepared by compression molding according to the ASTM D790 standard.

\section{Test for antimicrobial property}

Antimicrobial property of chitosan and nano-silver coated chitosan powders was studied by agar disk diffusion method. Gram positive bacteria (Staphylococcus aureus ATCC 25923 and Bacillus subtilis ATCC 6633), Gram negative bacteria (Escherichia coli ATCC 25922, Micrococcus luteus ATCC 9341 and Pseudomonas aeruginosa ATCC 27853) and fungus (Candida albicans ATCC 10231) were used in this study. All bacteria were incubated at $37{ }^{\circ} \mathrm{C}$ for $24 \mathrm{~h}$ while the fungus was incubated at $30{ }^{\circ} \mathrm{C}$ for $72 \mathrm{~h}$. Diameter of the inhibition zone was measured in order to evaluate the antimicrobial property.

Antimicrobial property of the hybrid materials of nanosilver coated chitosan and PLA was measured by quantifying the survival of bacterial cells according to JIS Z 2801. Firstly, 8 pieces of each specimen were put into the media with the microbe concentration of $1.5 \times 10^{5} \mathrm{cfu} / \mathrm{ml}$. Next, the media was shaken with the speed of 120 rpm at $37{ }^{\circ} \mathrm{C}$ for $24 \mathrm{~h}$. $100 \mathrm{~mL}$ of the solution was transferred to nutrient agar (NA) for bacteria and potato dextrose agar (PDA) for fungus and then incubated at $37^{\circ} \mathrm{C}$ for $24 \mathrm{~h}$. The antimicrobial activity is presented as percent reduction according to the formulation below.

Reduction $(\%)=(B-A) / A$ * 100

where

A : Number of bacteria recovered after dynamic contact of to the sample (at time of $24 \mathrm{~h}$ )

$B$ : Number of bacteria before the addition of the sample (at time 0 of $h$ )

\section{RESULTS AND DISCUSSION}

Synthesis, characterization and antimicrobial test of nanosilver coated chitosan

Physical appearances of chitosan and nanosilver coated chitosan are shown in Fig. 1(a) and $1(\mathrm{~b})$, respectively. It was observed that the nanosilver coated chitosan had darker color than uncoated chitosan. SEM image of chitosan (Fig. 1(c)) illustrates the smooth surface of the chitosan. For nanosilver-coated chitosan (Fig. 1(d)), there were small particles dispersing on the surface of the chitosan. This supported that the silver nanoparticles were successfully introduced to the surface of chitosan. Fig. 1(e) is the low-magnification SEM image for silver coated chitosan. Again, it revealed that silver nanoparticles were distributed evenly on the surface of chitosan. The result agreed with the XRF mapping (Fig. 1(f)) and XRF spectra (Figure 1(g))

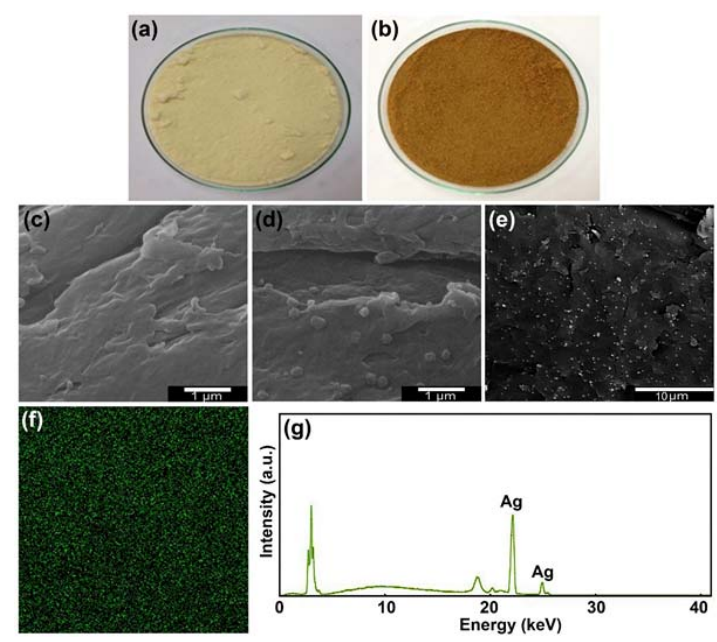

Fig. 1. Physical appearances of (a) pure chitosan and (b) nanosilver coated chitosan (2.5CS-Ag). SEM images of (c) pure chitosan, (d) and (e) nanosilver coated chitosan (2.5CS-Ag). (f) XRF mapping of $\mathrm{Ag}$ element for nanosilver coated chitosan (2.5CS-Ag). (g) XRF spectra for nanosilver coated chitosan (2.5CS-Ag)

FTIR spectra of the chitosan and nano-silver coated chitosans are shown in Fig. 2(a). FTIR spectrum of chitosan shows the peaks at 3600-3000, 2885, 1590, 1310 and $1149 \mathrm{~cm}^{-1}$ which were assigned to amino, hydroxyl, amide I, II and III respectively, consistent with the previous work from Tze-Wen Chung et al., ${ }^{28}$. However, the FTIR spectrum of nano-silver coated chitosan with various nano-silver contents were similar to pure chitosan. It can be concluded that the coating nano-silver on the surface of chitosan did not change the chemical structure of chitosan.

TGA thermograms of chitosan and nano-silver coated chitosan were shown in Fig. 2(b). 
On heating, the chitosan exhibited weight loss in three steps. The first weight loss around $26-107^{\circ} \mathrm{C}$ was corresponding to the moisture evaporation. The second weight loss from $107-323^{\circ} \mathrm{C}$ was caused by the hydrocarbon decomposition. The final weight loss from $323-537{ }^{\circ} \mathrm{C}$ was ascribed to the decomposition of the residual ash from chitosan. Nano-silver coated chitosan also showed weight loss in three steps like chitosan. However, the TGA thermograms of the nano-silver coated chitosan were found to have weight remaining at $1000{ }^{\circ} \mathrm{C}$ The final weight residues of $2.5 \mathrm{CS}-\mathrm{Ag}, 10 \mathrm{CS}-\mathrm{Ag}$, 15CS-Ag, and 20CS-Ag was 16.6, 8.4, 5.7 and 3.9 wt $\%$ respectively. This was because the metallic silver was left after the heat treatment. Moreover, the decomposition of the nanosilver coated chitosan occurred at the lower temperature than neat chitosan because the metallic silver acted as a catalyst for decomposition reaction.
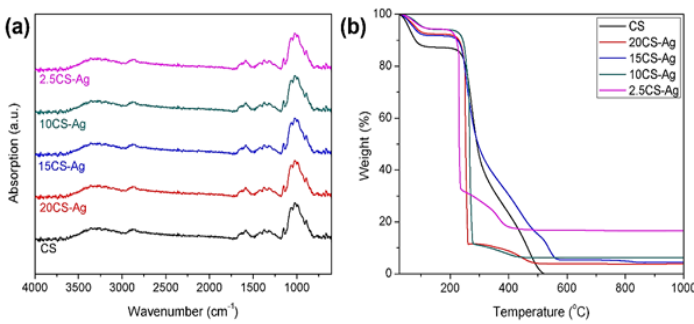

Fig. 2. (a) FTIR spectra and (b) TGA thermograms of chitosan and nanosilver coated chitosan with different silver contents

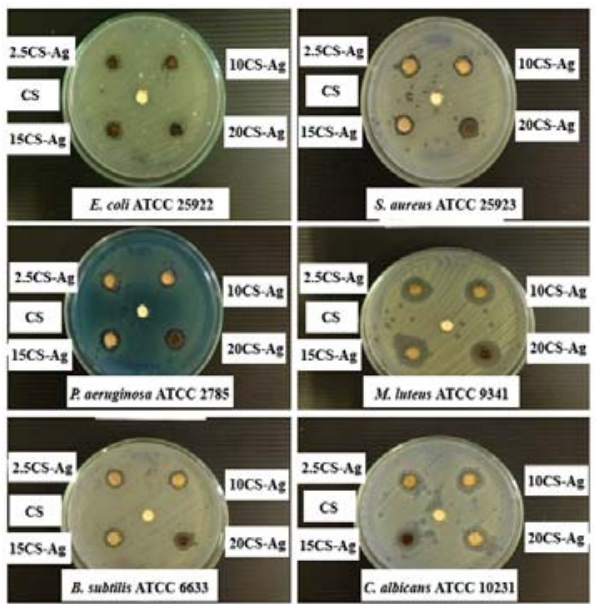

Fig. 3. Clear zones of chitosan and nanosilver coated chitosan against different types of microbes

Agar disk diffusion was used for antimicrobial testing of chitosan and nanosilver coated chitosan. Clear zones showing antimicrobial inhibitions are illustrated in Fig. 3 as well as Table 2. The result showed that pure chitosan did not exhibit the antimicrobial activity. This might be due to the chitosan was in the crystalline form. However, the nanosilver coated chitosan revealed antimicrobial property against all the microbes tested. From the table, the antimicrobial activities were similar. Therefore, only 10CS-Ag was used for further study.

Table 2: Clear zones of chitosan and nanosilver coated chitosan against different types of microbes

\begin{tabular}{lcccccc}
\hline Sample & \multicolumn{7}{c}{ Microbial strains (clear zone, cm) } \\
\cline { 2 - 7 } & E. coli & S. aureus & P. aeruginosa & M. luteus & B. subtilis & C. albicans \\
& ATCC & ATCC & ATCC & ATCC & ATCC & ATCC \\
& 25922 & 25923 & 2785 & 9341 & 6633 & 10231 \\
\cline { 2 - 7 } & - & - & - & - & - & - \\
CS & 1.33 & 1.31 & 1.71 & 2.23 & 1.30 & 1.72 \\
2.5 CS-Ag & 1.43 & 1.56 & 1.62 & 1.83 & 1.32 & 1.81 \\
10CS-Ag & 1.32 & 1.57 & 1.86 & 2.19 & 1.50 & 1.83 \\
15CS-Ag & 1.26 & 1.65 & 1.80 & 2.07 & 1.65 & 1.94 \\
20Cs-Ag & & & & & & \\
\hline
\end{tabular}

Fabrication, characterization, mechanical properties, and antimicrobial test of nanosilver coated chitosan and PLA composites

All the chitosan or nanosilver coated chitosan and PLA composites were fabricated using 10CS-Ag by compression molding method. The obtained composites were $1 \mathrm{phr}, 3 \mathrm{phr}, 5 \mathrm{phr}$ and $7 \mathrm{phr}$ of the 10CS-Ag filler in PLA matrix. The color of the obtained samples got darker with the higher content of the 10CS-Ag. XRF technique 
showed the silver peaks for all the composites with the 10CS-Ag filler. Moreover, the XRF mapping confirmed the good distribution of the silver in the polymer matrix.

TGA thermograms of the hybrid materials were shown in Fig. 4(a). Patterns of decomposition temperature of pure PLA and all of hybrid materials are similar. The initial decomposition temperature of all the samples are $50-100^{\circ} \mathrm{C}$. It was responsible for the loss of moisture. The second decomposition temperature of all the samples was $350-450^{\circ} \mathrm{C}$. For pure PLA, there was no residue left but the hybrid materials (1, 3, 5 and $7 \mathrm{phr}$ ) revealed the remaining product which was metallic silver with the content of $0.1,0.15,0.2$ and $0.3 \mathrm{wt} \%$, respectively. Moreover, the 7AgCS-PLA composite decomposed more rapidly than those of other PLA composites as well as neat PLA. The decomposition started at $320^{\circ} \mathrm{C}$. This would be due to the metallic silver behaving as a catalyst for thermal decomposition.
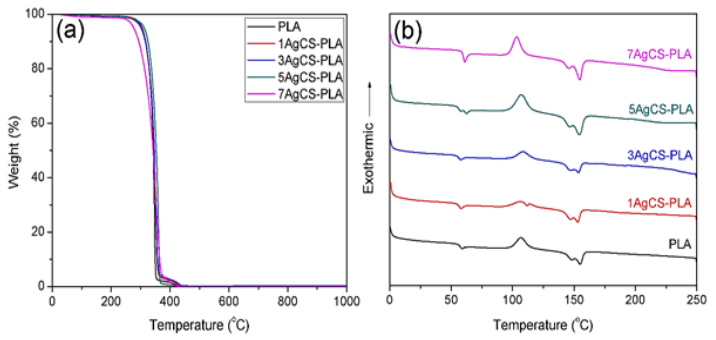

Fig. 4. (a) TGA and (b) DSC thermograms of PLA and nanosilver coated chitosan and PLA composites

DSC thermograms of neat PLA and the prepared hybrid materials are shown in Fig. 4(b). $T_{g}$ of the PLA was found to be about $59{ }^{\circ} \mathrm{C}$ while $\mathrm{T}_{g}$ of 1 phr (1AgCS-PLA) and 3 phr (3AgCS-PLA) was $57{ }^{\circ} \mathrm{C}$. When the content of nanosilver coated chitosan rose to $5 \mathrm{phr}$ (5AgCS-PLA), two $\mathrm{T}_{g}$ peaks of at 57 and $61{ }^{\circ} \mathrm{C}$ were observed. Moreover, the hybrid material with the content of nano-silver coated chitosan of $7 \mathrm{phr}$ (7AgCS-PLA) showed one peak of $T_{g}$ at $61^{\circ} \mathrm{C}$. This might be due to the nano-silver coated chitosan inserted in molecular chains of PLA. It caused space and free volume between molecules of PLA so that the molecular chains of PLA move easier leading to lower $T_{g}$. If the amount of the nanosilver coated chitosan was too much, the filler would block the movement of the PLA polymeric chains. As a result, the $T_{g}$ values of PLA increased again. $T_{c}$ peak of nanosilver coated PLA composites was decreased with the content of the filler. This was because the nanosilver coated chitosan filler behaved like a nucleating agent. It was observed that the $T_{c}$ temperature was changed from $114{ }^{\circ} \mathrm{C}$ to $105^{\circ} \mathrm{C}$. Moreover, the area under the $\mathrm{T}_{c}$ peak was also increased with the nanosilver coated chitosan content. This revealed that the crystallinity of the hybrid materials got higher. The result was in line with the $T_{m}$ temperature. For the hybrid material with high amount of nanosilver coated chitosan, $T_{m}$ signal was split to two peaks at 147 and $154^{\circ} \mathrm{C}$

Impact strength of the prepared materials is illustrated in Fig. 5(a). Neat PLA had the impact strength (absorbed energy) of $1.75 \mathrm{~kJ} / \mathrm{m}^{2}$ which was higher than all its composite materials. It was observed that nanosilver coated chitosan increased the brittleness of the composite materials. Impact strength was slightly increased with the amount of the filler. The impact strength for $1 \mathrm{phr}, 3 \mathrm{phr}$ and 5 phr samples were $1.26,1.30$ and $1.33 \mathrm{~kJ} / \mathrm{m}^{2}$, respectively.

However, the impact strength was decreased to $1.26 \mathrm{~kJ} / \mathrm{m}^{2}$ for the $7 \mathrm{phr}$ sample. This was because the filler strengthened the hybrid material but the impact force might be localized at only the certain position. Therefore, the impact strength of PLA was higher than all its composites. For the hybrid materials with nanosilver coated chitosan of $1 \mathrm{phr}, 3 \mathrm{phr}$ and $5 \mathrm{phr}$, the filler helped the PLA to receive the impact force leading to the slight increase in impact strength. However, the amount of nanosilver coated chitosan in $7 \mathrm{phr}$ sample was too high so the agglomeration of the filler made the hybrid material (7AgCS-PLA) more brittle. Moreover, the distribution of the impact force was very poor. Therefore, the impact strength of the 7 phr composite was the lowest. Flexural strength and percentage elongation of the hybrid materials are displayed in Fig. 5 (b) and (c), respectively. The testing procedure was followed the standard ISO14125 using the speed of $10 \mathrm{~mm}^{2} / \mathrm{min}$. The 
flexural strength and \% elongation of pure PLA were 178.8 $\mathrm{MPa}$ and 6.17 , respectively. Flexural strengths were 129.7, 109.1, 97.9, 97.4 MPa while the percentages of elongation were $3.7,3.5,3.4$ and 3.4 for 1 phr, 3 phr, 5 phr and 7 phr hybrid materials, respectively. The study on mechanical properties showed that the addition of the CS-Ag filler worsened the mechanical properties of PLA. However, the CS-Ag filler was still needed to improve the antimicrobial property of the hybrid materials.
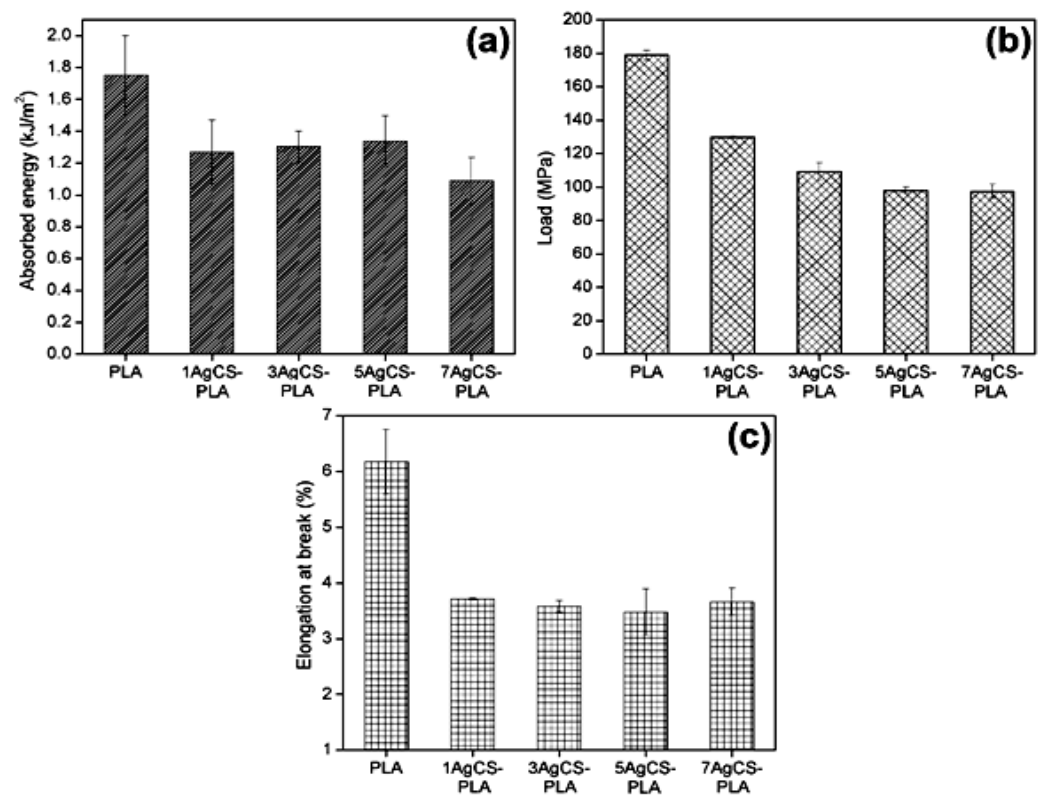

Fig. 5. (a) Impact strength, (b) Flexural strength and (c) percentage elongation of the prepared hybrid materials together with neat PLA
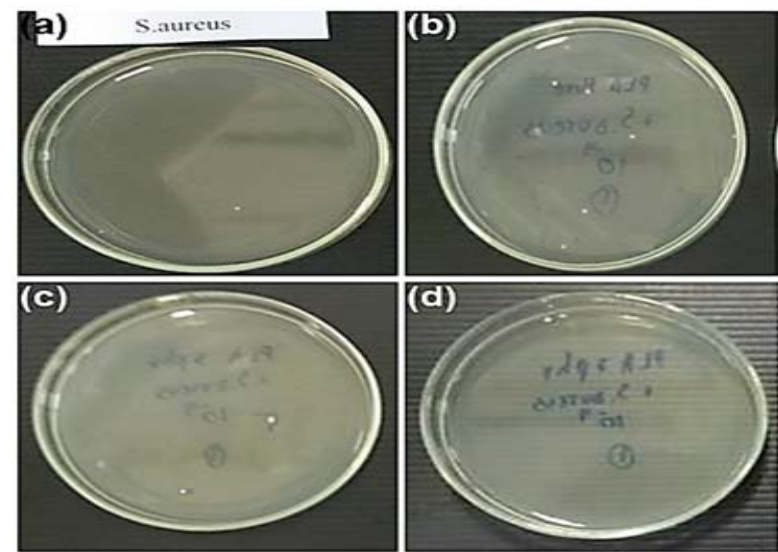

Fig. 6. Physical appearances of the petri dishes of $S$. aureus with initial concentrations of (a) $1.0 \times 10^{9}$ $\mathrm{cfu} / \mathrm{ml}$, (b) $4.0 \times 10^{9} \mathrm{cfu} / \mathrm{ml}$, (c) $3.0 \times 10^{4} \mathrm{cfu} / \mathrm{ml}$ and (d) $1.0 \times 10^{1} \mathrm{cfu} / \mathrm{ml}$. The sample used for (a), (b) and (c) is 3 AgCS-PLA while the sample used in (d) is 7AgCS-PLA 
Table 3: Antimicrobial property of the prepared hybrid materials against S.aureus

\begin{tabular}{lcccc}
\hline $\begin{array}{l}\text { Initial concentration of } \\
\text { S. aureus }(\mathrm{cfu} / \mathrm{ml})\end{array}$ & Sample & $\begin{array}{c}\text { No. of sample } \\
\text { (pieces) }\end{array}$ & $\begin{array}{c}\text { No. of colonies } \\
\text { dishes (cfu/ml) }\end{array}$ & $\begin{array}{c}\text { Percentage } \\
\text { inhibition }\end{array}$ \\
\hline $1.5 \times 10^{5}$ & S.aureus & - & $1.0 \times 10^{9}$ & - \\
$1.5 \times 10^{5}$ & PLA & 8 & $4.0 \times 10^{9}$ & neg \\
$1.5 \times 10^{5}$ & 3AgCS-PLA & 8 & $3.0 \times 10^{4}$ & 99.99 \\
$1.5 \times 10^{5}$ & 7AgCS-PLA & 8 & $1.0 \times 10^{5}$ & 99.99 \\
\hline
\end{tabular}

Table 4: Antimicrobial property of the prepared hybrid materials against $P$. aeruginosa

\begin{tabular}{lcccc}
\hline $\begin{array}{l}\text { Initial concentration of } \\
\text { P. aeruginosa }(\mathrm{cfu} / \mathrm{ml})\end{array}$ & Sample & $\begin{array}{c}\text { No. of sample } \\
\text { (pieces) }\end{array}$ & $\begin{array}{c}\text { No. of colonies } \\
\text { dishes (cfu/ml) }\end{array}$ & $\begin{array}{c}\text { Percentage } \\
\text { inhibition }\end{array}$ \\
\hline & P. aeruginosa & - & $4.0 \times 10^{7}$ & - \\
$1.5 \times 10^{5}$ & PLA & 8 & $8.0 \times 10^{7}$ & neg \\
$1.5 \times 10^{5}$ & 3AgCS-PLA & 8 & $1.0 \times 10^{4}$ & 99.99 \\
$1.5 \times 10^{5}$ & 7AgCS-PLA & 8 & $1.0 \times 10^{4}$ & 99.99 \\
\hline
\end{tabular}

Table 5: Antimicrobial property of the prepared hybrid materials against $E$. coli

\begin{tabular}{lcccc}
\hline $\begin{array}{l}\text { Initial concentration } \\
\text { of } E \text {. coli }(\mathrm{cfu} / \mathrm{ml})\end{array}$ & Sample & $\begin{array}{c}\text { No. of sample } \\
\text { (pieces) }\end{array}$ & $\begin{array}{c}\text { No. of colonies } \\
\text { dishes }(\mathrm{cfu} / \mathrm{ml})\end{array}$ & $\begin{array}{c}\text { Percentage } \\
\text { inhibition }\end{array}$ \\
\hline $1.5 \times 10^{5}$ & E. coli & - & $41.0 \times 10^{7}$ & - \\
$1.5 \times 10^{5}$ & PLA & 8 & $1.0 \times 10^{7}$ & neg \\
$1.5 \times 10^{5}$ & 3AgCS-PLA & 8 & $2.0 \times 10^{4}$ & 99.98 \\
$1.5 \times 10^{5}$ & 7AgCS-PLA & 8 & $2.0 \times 10^{4}$ & 99.98 \\
\hline
\end{tabular}

Table 6: Antimicrobial property of the prepared hybrid materials against $B$. subtilis

\begin{tabular}{lcccc}
\hline $\begin{array}{l}\text { Initial concentration of } \\
\text { B. subtilis }(\mathrm{cfu} / \mathrm{ml})\end{array}$ & Sample & $\begin{array}{c}\text { No. of sample } \\
\text { (pieces) }\end{array}$ & $\begin{array}{c}\text { No. of colonies } \\
\text { dishes }(\mathrm{cfu} / \mathrm{ml})\end{array}$ & $\begin{array}{c}\text { Percentage } \\
\text { inhibition }\end{array}$ \\
\hline $1.5 \times 10^{5}$ & B. subtilis & - & $2.0 \times 10^{8}$ & - \\
$1.5 \times 10^{5}$ & PLA & 8 & $65.0 \times 10^{8}$ & neg \\
$1.5 \times 10^{5}$ & 3AgCS-PLA & 8 & $1.0 \times 10^{4}$ & 99.99 \\
$1.5 \times 10^{5}$ & 7AgCS-PLA & 8 & $1.0 \times 10^{3}$ & 99.99 \\
\hline
\end{tabular}

Table 7: Antimicrobial property of the prepared hybrid materials against $C$. albicans

\begin{tabular}{lcccc}
\hline $\begin{array}{l}\text { Initial concentration of } \\
\text { C. albicans (cfu/ml) }\end{array}$ & Sample & $\begin{array}{c}\text { No. of sample } \\
\text { (pieces) }\end{array}$ & $\begin{array}{c}\text { No. of colonies } \\
\text { dishes }(\mathrm{cfu} / \mathrm{ml})\end{array}$ & $\begin{array}{c}\text { Percentage } \\
\text { inhibition }\end{array}$ \\
\hline $1.5 \times 10^{5}$ & C. albicans & - & $40.0 \times 10^{5}$ & - \\
$1.5 \times 10^{5}$ & PLA & 8 & $2.0 \times 10^{6}$ & neg \\
$1.5 \times 10^{5}$ & 3AgCS-PLA & 8 & $1.0 \times 10^{5}$ & 95.00 \\
$1.5 \times 10^{5}$ & 7AgCS-PLA & 8 & $2.0 \times 10^{5}$ & 90.00 \\
\hline
\end{tabular}




\section{CONCLUSION}

The nano-silver coated chitosan (CS-Ag) was successfully synthesized under mild condition by mixing silver nitrate and benzoxazine, the reducing agent, with chitosan powder. SEM images showed that the nanosilver particles were spherical shape with a uniform size and well dispersed and coated on chitosan surface. Different CS-Ag powders were prepared using the fixed amount of silver nitrate and the reducing agent but various masses of chitosan. The CS-Ag powders prepared from 2.5, 10, 15 and $20 \mathrm{~g}$ of chitosan were called 2.5CB-Ag, 10CB-Ag, 15CB-Ag and 20CB-Ag, respectively. TGA study revealed that the masses of silver residual after thermal decomposition of chitosan for 2.5CB-Ag, 10CB-Ag, 15CB-Ag and 20CB-were 16.6, 8.4, 5.7 and $3.9 \mathrm{wt} \%$ respectively. From the antimicrobial test, 10CS-Ag was the best one as it showed relatively good activity and it had relatively low silver content compared to other CSAg powders. Therefore, 10CS-Ag was selected to use for fabrication of AgCS-PLA hybrid materials. The compound pellets of CS-Ag and PLA were prepared, and the melt flow index (MFI) of the pellets was investigated. The MFI result suggested that compression molding method was used to make AgCS-PLA hybrid materials.
Thermal analysis of AgCS-PLA hybrid materials showed that the nanosilver acted as a catalyst for thermal decomposition and lower the decomposition temperature of the hybrid materials. Moreover, it behaved like a nucleating agent for polylactic acid so that the crystallization peak decreased but its area increased. Even though, the CS-Ag filler lowered the mechanical properties of hybrid materials, it was still required to improve the antimicrobial property of the hybrid materials. According to this work, 3AgCS-PLA hybrid materials showed microbial inhibition up to $99.99 \%$ when tested by the method of the JIS Z 2801 standard. Therefore, our work reported the possibility of developing the AgCS-PLA hybrid materials as novel biodegradable and antimicrobial materials for certain applications.

\section{ACKNOWLEDGEMENT}

The authors would like to thanks Kasetsart University Research and Development Institute (KURDI), Kasetsart University and Rajamangala University of Technology Thanyaburi for their financial supports.

\section{REFERENCES}

1. Jambeck, J.R.; Geyer, R.; Wilcox, C.; Siegler, T.R.; Perryman, M.; Andrady, A.; Narayan, R.; Law, K.L. Science., 2015, 347, 768-771.

2. Derraik, J.G.B. Mar. Pollut. Bull., 2002, 44, 842-852.

3. Al-Salem, S.M.; Lettieri, P.; Baeyens, J. Waste Manag., 2009, 29, 2625-2643.

4. Ren, X. J. Clean. Prod., 2002. 11, 27-40.

5. González-García, D.M., Téllez Jurado, L., Jiménez-Gallegos, R., Rodríguez-Lorenzo, L.M. Mater. Sci. Eng. C., 2017, 75, 375-384.

6. Aenel, S.; McClure, S.J. Adv. Drug. Deliv., Rev. 2004, 56, 1467-1480.

7. Jayakumar, R.; Menon, D.; Manzoor, K.; Nair, S.V.; Tamura, H. Carbohydr. Polym., 2010, 82, 227-232.

8. Sadeghi-Kiakhani, M.; Gharanjig, K.; Arami, M. J. Ind. Eng. Chem., 2015, 28, 78-85.
9. Dash, M.; Chiellini, F.; Ottenbrite, R.M.; Chiellini, E. Prog. Polym. Sci., 2011, 36, 981-1014.

10. Kong, M.; Chen, X.G.; Xing, K.; Park, H.J. Int. J. Food. Microbiol., 2010, 144, 51-63.

11. Lee, S.-H.; Kim, M.-J.; Park, H. J. Appl. Polym. Sci., 2010, 117, 623-628.

12. Alonso, D.; Gimeno, M.; Olayo, R.; VázquezTorres, H.; Sepúlveda-Sánchez, J.D.; Shirai, K. Carbohydr. Polym., 2009, 77, 536-543.

13. Dev, V.R.G.; Venugopal, J.; Sudha, S.; Deepika, G.; Ramakrishna, S. Carbohydr. Polym., 2009, 75, 646-650.

14. Crini, G.; Badot, P.-M. Prog. Polym. Sci., 2008, 33, 399-447.

15. Wan Ngah, W.S.; Teong, L.C.; Hanafiah, M.A.K.M. Carbohydr. Polym., 2011, 83, 1446-1456.

16. Sadeghi-Kiakhani, M.; Safapour, S. Clean Technol. Environ. Policy., 2015, 17, 1019-1027. 
17. Sadeghi-Kiakhani, M.; Safapour, S. Fiber. Polym., 2015, 16, 1075-1081.

18. Clement, J. L.; Jarrett, P. S. Met. Based Drugs., 1994, 1, 467-482.

19. Chen, X.; Schluesener, H.J. Toxicol. Lett., 2008, 176, 1-12.

20. Galeano, B.; Korff, E.; Nicholson, W.L. Appl. Environ. Microbiol., 2003, 69, 4329-4331.

21. Thomas, S.; McCubbin, P. J. Wound Care., 2003, 12, 305-308.

22. Rabea, E.I.; Badawy, M.E.-T.; Stevens, C.V.; Smagghe, G.; Steurbaut, W. Biomacro molecules., 2003, 4, 1457-1465.

23. Farouk, A.; Moussa, S.; Ulbricht, M.; Textor, T. Int. J. Carbohydr. Chem., 2012, 2012, e693629.
24. AbdElhady, M. M. Int. J. Carbohydr. Chem., 2012, 2012, e840591.

25. Akmaz, S.; Dilaver Adgüzel, E.; Yasar, M.; Erguven, O. Adv. Mater. Sci. Eng., 2013, 2013, e690918.

26. Arif, D.; Niazi, M. B. K.; Ul-Haq, N.; Anwar, M. N.; Hashmi, E. Fiber. Polym., 2015, 16, 1519-1526.

27. Kaewvilai, A.; Wattanathana, W.; Jongrungruangchok, S.; Veranitisagul, C.; Koonsaeng, N.; Laobuthee, A. Mater. Chem. Phys., 2015, 167, 9-13.

28. Wattanathana, W.; Nonthaglin, S.; Veranitisagul, C.; Koonsaeng, N.; Laobuthee, A. J. Mol. Struct., 2014, 1074, 118-125.

29. Chung, T.-W.; Chang, C.-H.; Ho, C.-W. J. Taiwan Inst. Chem. Eng., 2011, 42, 592-597. 